\title{
AS BRUMAS DE AVALON: UMA LEITURA ECOFEMINISTA
}

\author{
THE MISTS OF AVALON: AN ECOFEMINIST READING
}

\begin{abstract}
RESUMO
As teorias ecofeministas buscam responder sobre projeto de futuro e modelos de sociedade, respaldando-se em um futuro ancestral. A literatura, enquanto expressão cultural de uma época, traduz paradigmas de pensamento do seu tempo de gestação. O ecofeminismo cresce na década de 1970, mesmo período em que As Brumas de Avalon, de Marion Zimmer Bradley, é lançada. Tal obra rememora um passado narrando estruturas matriarcais na sociedade e na religião. O objetivo deste artigo consiste em analisar os pontos ecofeministas presentes na referida ficção, utilizando autoras como Mary Mellor, Mary Daly e Ynestra King. Inicialmente, são apresentadas as bases do ecofeminismo. Em ato contínuo, explana-se o enredo para, finalmente, discutir e apontar os pontos de intersecção ecofeminista presentes no livro. A metodologia utilizada é de base exploratória e hipotético-dedutiva, por meio de técnicas bibliográficas. As reflexões indicam que é possível o entendimento da manifestação ecofeminista em As Brumas de Avalon.
\end{abstract}

Palavras-chave: Ecofeminismo. As Brumas de Avalon. Marion Zimmer Bradley.

\begin{abstract}
Ecofeminist theories seek to answer about the future projects and models of society, based on na ancestral future. Literature, as a cultural expression of na era, translates paradigms of thought from its time of gestation. Ecofeminism grew in the 1970s, the same period as Marion Zimmer Bradley's The Mists of Avalon was launched. This book reminds a past matriarchal structure in society and religion. The aim of this pape ris to analyze the ecofeminist aspects in that fiction, using authors such as Mary Mellor, Mary Daly and Ynestra King. First, the foundations of ecofeminism are presented. Continuously, the plot is explained to finally discuss and point out the ecofeminist intersection presented in the novel. The methodology used is exploratory and hypothetical-deductive, using bibliographic thechiniques. The reflections indicate that it is possible to understand the ecofeminist manifestation in The Mists of Avalon.
\end{abstract}

Keywords: Ecofeminism. The Mists of Avalon. Marion Zimmer Bradley.

Émilien Vilas Boas Reis

Escola Superior de Ensino Dom Helder Câmara.

Vanessa Lemgruber

Escola Superior de Ensino Dom Helder Câmara. Email: vanessalemgruberı@gmail.com 


\section{Introdução}

Inúmeras são as formas de visualizar o meio ambiente. Nas sociedades contemporâneas, a conexão dos seres com a natureza esvai-se à medida que práticas industriais os afastam da terra. O ecofeminismo propõe o incentivo da interconectividade, abordando a subjugação das mulheres sob a mesma égide da depredação ambiental, no reconhecimento de injustiças e de tratamentos marginalizantes.

$\mathrm{O}$ pensamento ecofeminista propõe que as causas dos maus-tratos às mulheres e ao meio ambiente surgem do mesmo lugar, qual seja, a cultura patriarcal assentada em valores universalistas de dominação, exploração, guerra e conquista. Essa origem em comum pode ser alterada na revalorização do cuidado, do amor e do cooperativismo.

Igualmente, a relação da humanidade com o meio ambiente tem sido revista no intuito de se responsabilizar pelo bem-viver desta geração e o de futuras. A presença cotidiana de temas como mudanças climáticas, lixo zero, veganismo, ecologia e direito das mulheres representa a urgência de se repensar padrões culturais préestabelecidos e binaristas, tais quais, homem/natureza; natural/cultural e homem/ mulher.

Analogias binaristas sobre o mundo tendem a excluir ou a adjetificar negativamente um dos aspectos da relação. Por exemplo, o padrão natural versus cultural parece evidenciar o bom e o mau. Ou seja, que se deve escolher entre um ou outro; e, ao fazê-lo, automaticamente elege-se o desejável e o indesejável.

No repensar dessas relações dicotômicas, o ecofeminismo emerge enquanto importante luz, no intuito de perceber a realidade em seus aspectos múltiplos, diversos e não excludentes. Esse paradigma trata da questão ambiental relacionada com o papel da mulher, a importância dos seres não humanos e o resgate de culturas pré-patriarcado na intenção de um futuro ancestral. ${ }^{1}$

Nesses termos, a lente ecofeminista enxerga o homem como o agente produtor de uma cultura vista como normal e desejável numa sociedade assentada em valores patriarcais, penosamente sofredora de diversos problemas ambientais e éticos. Ao mesmo passo, entende a mulher enquanto ser intrínseca, biológica e socialmente conectada à natureza e aos ciclos vitais.

Porém, além de conectada à natureza, a mulher também é produtora de cultura. Visto, pois, que o paradigma ecofeminista questiona as dicotomias excludentes, não haveria assim de prosseguir com a associação do ser mulher apenas à natureza, mas considerar também a própria produção cultural humana enquanto parte do experenciar da vida. Da mesma forma, o ser homem também pode estar conectado

1 Futuro ancestral sinaliza o uso de manifestações contemporâneas na expressão de técnicas de tribos e de comunidades antigas, com o intuito de reverberar de forma humanizada e coletiva a integração com a natureza e consigo mesma. O caminho para a posteridade sustentável passa pela revisitação da sabedoria antiga (MOURÃO, 1997). 
à natureza, de sua própria forma, se assim desejar romper com as dicotomias limitadoras de uma visão múltipla da realidade.

O paradigma ecofeminista, apesar do nome ser ainda pouco difundido, tem suas bases expressas no fazer cultural. A literatura, enquanto locus de personagens emblemáticas, expressa os medos e as esperanças sociais de seu tempo de gestação. E mais: demonstra ludicamente pensamentos filosóficos do espírito de seu tempo.

Tendo isso em vista, o ecofeminismo cresce na década de 1970, mesmo período no qual são escritos os livros que compõem As Brumas de Avalon, de Marion Zimmer Bradley. A primeira publicação data de $1979 .^{2}$

A coletânea clássica trata das histórias do rei Arthur e dos Cavaleiros da Távola Redonda, que, antes de se tornarem lenda, foram miticamente construídas ao lado de potentes mulheres, mostradas pela primeira vez em primeiro plano.

Feitas tais considerações, o tema-problema do estudo reside na existência de ideais ecofeministas em As Brumas de Avalon.

No percurso investigativo do referido tema-problema, cujo objetivo geral concentra-se na análise da temática ecofeminista em As Brumas de Avalon, são considerados os seguintes objetivos específicos: explanar bases teóricas do ecofeminismo, discorrer sobre o enredo da literatura em tela e relacioná-la com a teoria.

Assim, formula-se a hipótese da manifestação ecofeminista em As Brumas de Avalon.

90 No decorrer analítico da hipótese, a presente pesquisa lança mão dos seguintes parâmetros metodológicos: quanto à abordagem do problema, qualitativa; quanto aos objetivos, descritiva e explicativa; quantos aos métodos, hipotético-dedutivo; quanto às técnicas, bibliográfica e documental; e quanto aos instrumentos, análise de conteúdo.

Como marco teórico, foram adotados os escritos ecofeministas de Mary Mellor, Mary Daly e Ynestra King, bem como a obra literária de Marion Zimmer Bradley.

\section{Ecofeminismo}

O Ecofeminismo trata-se de um novo termo para uma antiga sabedoria. A ideia de uma mãe provedora é um tanto quanto marcante, e, talvez por isso, o Planeta é visto como um ser provedor de alimento, morada e bênçãos, tal qual a figura materna. Porém, da mesma forma que o patriarcado mostra uma faceta temerária no trato com as mulheres, a relação com o meio ambiente e a exploração dos bens naturais se mostram tão pouco gentis quanto.

O ecofeminismo situa-se tanto na linha histórica do movimento de mulheres quanto nos debates ambientalistas. Na seara feminista, constitui-se como

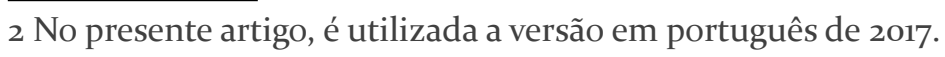


manifestação da vertente do feminismo da diferença. Na ambientalista, da fase holística.

O feminismo da diferença nasce das bases do feminismo radical e toma para si o vocábulo diferença, apropriando-o de forma positiva, pois é nela que a mulher se liberta, encontra sua identidade e deixa de lado as referências padronizadas de um ideal masculino. Para esse feminismo, o caminho da liberdade se inicia com a distinção sexual e a apropriação empoderada e orgulhosa de suas especificidades (Garcia, 2015: 1140-1144).

O genérico masculino instituiu-se como monopolizador de legitimação da vida, de posicionar-se como a medida do ser humano ideal. Ao feminino seria relegada a tentativa de alcançar o masculinizante. Ou seja, o feminino enquanto oposto do referencial tratar-se-ia de um atributo menos valioso.

A simples igualdade entre homens e mulheres poderia significar a aceitação do modelo masculino de sociedade (Garcia, 2015: 1144-1148). Além disso, seria o disfarce mais sagaz daqueles que defendem a inferioridade das mulheres (Garcia, 2015: 1178).

A verdadeira igualdade não consiste na equivalência de sexos. Poder-se-ia, de fato, utilizar-se a palavra equidade, pois cada pessoa deve ser igualmente respeitada levando em consideração seus específicos quereres e necessidades. Nesses termos, a contribuição do feminismo da diferença pode ser sintetizada da seguinte forma: só há liberdade de pensamento com o pensamento da diferença sexual, sem um padrão masculino ao qual todas devem e querem alcançar (Garcia, 2015: 1194-11948).

Por sua vez, a fase holística do movimento ambiental é marcada pela abordagem ecossistêmica do meio ambiente (França, 2016: 17), visando à compatibilização do desenvolvimento com o equilíbrio ecológico, no auge das campanhas antinucleares, na crise da modernidade e do imperialismo econômico (Mellor, 2000: 66), requerendo soberania alimentar e o direito para espécies não humanas.

Tanto o feminismo da diferença quanto a fase holística têm suas primeiras marcações temporais na década de 1970 em diante. Da confluência dessas ideias, o ecofeminismo toma corpo, voz e forma.

O cerne do ecofeminismo, portanto, trata de forma indissociável a proteção ambiental com a equidade das mulheres. O surgimento da vertente ecofeminista se dá ao longo das décadas de 1970 e 1980, sob uma roupagem inicialmente essencialista, e consiste na leitura a partir do movimento de mulheres para a filosofia e para a prática ambiental (França, 2019: 140), no passo em que conectam o jugo com o qual mulheres eram tratadas e os abusos na natureza.

O ecofeminismo se desenvolveu em diversas partes do globo (França, 2019: 153), em um período de florescimento tanto do feminismo quanto do ambientalismo radical. Entretanto, o termo aparece pela primeira vez em 1974, na obra Le Féminisme ou la Mort, ${ }^{3} \mathrm{da}$ francesa Françoise D'Eaubonne (1980). Ela conecta a relação entre o direito das mulheres e o ambiente de forma indissociável, ao afirmar que todos os feminismos desembocaram na proteção da natureza; e todo movimento ambientalista deságua na defesa dos direitos das mulheres.

3 Tradução livre: $\mathrm{O}$ feminismo ou a morte. 
$\mathrm{O}$ argumento de Françoise reside na necessidade do movimento ambiental em enxergar o planeta como feminino (D’Eaubonne, 1980: 64-67), para assim extirpar o controle masculino da produção industrial e da sexualidade. Ato contínuo, discorre sobre questões centrais, como a crise do pensamento progressista e o custo ecológico do viés desenvolvimentista, a indicação da mentalidade do homem médio como causa dos problemas ambientais, o chamado para que as mulheres sejam as agentes protagonistas de mudanças positivas e defesa da centralização do poder nas mulheres.

Porém, ainda que a atribuição inicial seja majoritariamente conferida à escritora francesa Françoise D’Eaubonne (1980), no mesmo ano de 1974, a estadunidense Chiah Heller lança mão do termo ecofeminismo social. No período, também ocorreram protestos no norte a Índia contra madeireiras por mulheres, bem como tradições em países da Escandinávia e da América do Sul com conteúdo similar (Salleh, 1991: 206).

Independentemente do país, a caracterização teórica ecofeminista repousa em três pontos: (1) explora a natureza das conexões entre as dominações injustificadas das mulheres e a natureza; (2) critica as visões filosóficas ocidentais masculinas, em suas suposições, conceitos, afirmações, distinções, posições e teorias sobre mulheres e natureza; e (3) cria alternativas e soluções para essas visões tendenciosas pensadas por homens (Warren, 2015) sob a lógica patriarcal.

Esses três pontos basilares de desenvolvimento teórico evidenciam que o ecofeminismo transfere para a natureza o cuidado tido como vocação ancestral das mulheres, sem distinção para com as figuras humanas e não humanas, adultas e crianças, casa e espaço público (Ferreira, 2009: 234).

A teoria ecofeminista, de forma geral, parte de duas grandes matrizes que, vez ou outra, se interseccionam. São elas: a matriz de manifestação essencialista ou espiritual e a matriz social. Ambas, porém, são culturais, pois, ao afirmarem uma acepção paradigmática, estão imbuídas no seu próprio contexto de pensamento.

Sob a égide do ecofeminismo essencialista ou espiritual, a estadunidense e ex-teóloga católica Mary Daly introduz o ecofeminismo a seus estudantes em Boston e na Universidade da Califórnia (Mellor, 2000: 60-70). Em sua obra Beyond God the Father - Toward a Philosophy of Women's Liberation (DALY, 1993), ${ }^{4}$ Mary Daly ressalta no feminismo a afinidade natural das mulheres com a natureza. Dos livros escritos por ela, foi o último a tomar Deus como um assunto subjetivo e a ponderar sobre a teologia ocidental.

Ela inicia sua trajetória no feminismo sob a óptica cultural, exigindo o reconhecimento das, assim ditas pela autora, especificidades femininas, e da construção de uma sociedade na qual as mulheres possam se expressar sem qualquer controle alheio a suas vontades. Ademais, prega a superioridade do corpo e dos valores femininos (Ferreira, 2009: 237).

Os estudos de Mary Daly desembocam no ecofeminismo quando ela percebe estarem "as mulheres mais próximas da natureza visto que o ciclo da vida está presente

4 Tradução livre: Além de Deus, o Pai - Rumo a uma filosofia de libertação das mulheres. 
nos seus corpos, nos seus ritmos e processos, na geração, gestação, nascimento, etc." (Ferreira, 2009: 237).

A inserção de Daly no ecofeminismo fica clara no livro Gyn/Ecology. The Metaethics of Radical Feminism (Daly, 1990), 5 de sua autoria. O nome da obra já indica em si o posicionamento contido no interior de suas páginas; pois, ao fazer um trocadilho com a palavra ginecologia, ao desmembrá-la em gin-e-ecologia, respectivamente, alude à figura da mulher, por meio do útero, e às relações dos seres na natureza.

Além de indicar a posse patriarcal do existir das mulheres por meio de doutores do espírito, da mente e do corpo: padres e gurus, psiquiatras e médicos ginecologistas (Ferreira, 2009: 239); Daly elenca uma série de costumes ancestrais perpetrados em desfavor do feminino. A saber, a prática indiana de queimar as viúvas na mesma pira funerária de seus maridos; a cultura chinesa de considerar erótico pés pequenos e, por isso, enfaixar os de jovens meninas, causando deformação; mutilação genital feminina em alguns países do continente africano; tortura e caça às bruxas nas sociedades europeias nos séculos XV e XVII (Ferreira, 2009: 240).

Na obra Gyn/Ecology, Mary Daly aduz que o poder paralisante e castrador expresso pelo patriarcado é a raiz da violência corpórea, mental e espiritual da natureza feminina (Ferreira, 2009: 237). Em seus dizeres:

O fato é que vivemos em uma sociedade profundamente antifeminina (sic), uma misógina "Civilização" na qual os homens vitimam coletivamente as mulheres, atacando-nos como personificações de seus próprios medos paranoicos, como $\mathrm{O}$ Inimigo. Dentro dessa sociedade, são homens que estupram, que seivam e podam a energia das mulheres, que negam às mulheres poder político. Permitir-se conhecer e nomear esses fatosécometer atos anti-ginecídicos (sic). Agindo desta forma, movendo-se através dos labirintos de uma sociedade anti-feminina, exige nomear e superar os obstáculos construídos pelo seu agente e instrumentos femininos simbólicos. Como uma cristalização criativa do movimento para além do Estado de Paralisia Patriarcal, este livro é um ato de Despossessão; e, portanto, em um sentido além das limitações do rótulo anti-masculino (sic), é absolutamente Anti-androcrata (sic), In-crivelmente Anti-masculino (sic), Furiosa e Definitivamente Feminino (DALY, 1990: 29). ${ }^{6}$

5 Tradução livre: Gin/ecologia. A Metaética do Feminismo Radical.

6 No original: The fact is that we live in a profoundly anti-female society, a misogynistic "civilization" in which men collectively victimize women, attacking us as personifications of their own paranoid fears, as The Enemy. Within this society it is men who rape, who sap women's energy, who deny women economic and political power. To allow oneself to know and name these facts is to commit anti-gynocidal acts. Acting in this way, moving through the mazes of anti-female society, requires naming and overcoming the obstacles constructed by its male agents and token female instruments. As a creative crystallizating of the movement beyond the State of Patriarchal Paralysis, this book is an act of Dispossession; and hence, in a sense beyond the limitations of the label anti-male, it is absolutely Anti-androcrat, A-mazingly Antimale, Furiously and Finally Female. 
Conforme o trecho acima, Mary Daly é um tanto quanto eloquente em seu posicionamento pró-feminino, ao incitar a ideia de que a questão ecológica é uma exclusividade das mulheres, pois apenas elas seriam verdadeiramente sensíveis ao trato natural (Ferreira, 2009: 238).

Porém, tal segregação da humanidade entre homens e mulheres, machos e fêmeas, bem como a relegação do destino do planeta apenas nelas, não parece adequado. Além de ser mais um peso de consertarem os males ambientais evidenciados pela lógica patriarcal, exime os homens/machos da responsabilidade e desconsidera outras existências humanas não enquadrantes nos modelos de representatividade dual e fechada.

Ainda nesse sentido de binarização do sexo, Mary Daly era assumidamente contra a transsexualidade nos debates ecofeministas, pois, para ela, haveria a monopolização da transição do masculino para o feminino. Segundo a autora, seria uma invasão das reivindicações das fêmeas por machos, incapazes de realmente assumirem os cromossomos femininos por meio de nenhuma cirurgia nem terapia hormonal (Daly, 1990: 68-71).

Apesar de bastante polêmico, não se deve fechar os olhos à coletânea de pensamentos de uma escritora. Nesse sentido, a obra de Mary Daly foi bastante criticada, pois desconsidera completamente as especificidades étnicas e coloca todas as mulheres em um mesmo essencialismo que, em verdade, relaciona-se a mulheres brancas, nascidas fêmeas, com elevado poder aquisitivo e do Norte Global (Mellor, 2000: 67). Ora, o ecofeminismo critica os dualismos de dominação. Não deve, pois, mantê-los por nenhum motivo.

Mas, não obstante a crítica exposta, a espiritualidade ecofeminista levanta quatro questionamentos. Primeiro, a imagem e a linguagem de um Deus exclusivamente masculino. Segundo, a divisão entre corpo e alma, que reflete a segregação entre mente e intelecto, coloca a carne como pecado e a vida da Terra como preparação para o Reino dos Céus. Terceiro, o resgate e a reivindicação da experiência e da história espiritual das mulheres. Quarto, o estabelecimento de bases para uma teologia e rituais em respeito ao feminino (Mellor, 2000: 73).

A espiritualidade feminina está baseada na terra, e não dirigida ao céu, na medida em que enxerga a mulher na forma de Deusa e celebra a natureza espiritual do mundo físico e do corpo feminino. Nesse sentido, muitas ecofeministas tentam recuperar o mundo místico perdido de antigas religiões pagãs ${ }^{7}$ baseadas no contato com a terra (Mellor, 2000: 73).

Tendo isso dito, é como se todas as fases da mulher fossem consideradas sagradas pela espiritualidade ecofeminista: nascimento, menstruação, menopausa. Representam a criatividade de ser mãe e se multiplicar, e a juventude com a adolescência, a sabedoria (Mellor, 200o: 75). Nesse sentido, celebrar o ciclo menstrual e outros tabus relacionados ao corpo feminino impostos por religiões patriarcais é uma forma reivindicativa dos corpos e da sexualidade das mulheres, ou seja, de se

7 Entendemos pagãs como manifestações religiosas diversas, de cunho politeísta ou não, associadas ao judaísmo, cristianismo ou islamismo. 
reestabelecerem em contato com a natureza, na figura de uma deusa. Nesse sentido, Mary Daly defende a necessidade de as mulheres crerem num místico feminino como o equivalente da busca do reino dos céus defendida pelo judaico-cristianismo (Mellor, 2000: 75).

Além da espiritualidade, há o pensamento ecofeminista construído sob a matriz social. Ou melhor, também sob a matriz social, ${ }^{8}$ pois não o é completamente. O ecofeminismo tende a levar em conta as variáveis biológicas e cosmológicas de poder em torno da corporificação humana (Mellor, 2000: 79).

O ecofeminismo de viés social nasce porque as teorias sobre justiça raramente abarcam de forma clara as disparidades entre sexos e gêneros, muito menos priorizam a proteção ambiental. Geralmente, ao se falar em termos sociais, privilegia-se o aspecto econômico da renda familiar, não abarcando, assim, a realidade de dominação dos corpos femininos e da natureza.

A matriz ecofeminista social tem em Ynestra King um vínculo entre teoria e ativismo político radical. Ela foi fundadora e organizadora tanto da Conferência sobre as Mulheres e a Vida na Terra de 1980 como de Ações das Mulheres frente ao Pentágono em 1980-1981, que lançaram o ecofeminismo como um movimento. Antes, ela esteve ligada a uma larga história de ativismo feminista e pacifista (Mellor, 2000: 79-80).

King, ao apontar que o pensamento de Mary Daly é dualista e pretenso ao afirmar verdades de uma teologia matriarcal no lugar de uma patriarcal, dele se dissocia (Mellor, 2000: 80). Ela apresenta os seguintes pontos como principais do ecofeminismo: a crítica ao dualismo da sociedade patriarcal ocidental, que distingue humanidade - homem - do mundo natural - mulher -; a posição de subordinação das mulheres e da natureza nesse dualismo; a necessidade de criar uma conexão não descritiva entre a humanidade - o homem - e o mundo natural - mulher -; e o papel fundamental das mulheres para a criação dessa conexão (Mellor, 2000: 81).

Nesse sentido, King afasta a ideia de que as mulheres devem abandonar sua associação com a natureza e se unir ao normal masculino, pois isso seria abraçar as culturas dominadoras da feminilidade e da natureza (Mellor, 2000: 81). Palavras outras, ainda que a construção do feminino e sua aproximação pelo cuidado na proteção do meio ambiente tenham sido postas por um pensamento patriarcalmente embasado, repelir tal afirmação seria corroborar o menosprezo e o desvalor já estabelecidos ao cuidado e ao zelo com a casa comum e com existências diversas.

O núcleo aproximador entre o ecofeminismo social e o feminismo de afinidade/essencialista reside no fato de que todos os seres humanos estão arraigados na natureza enquanto seres corpóreos. Entretanto, para as ecofeministas sociais, as mulheres estão tão imbuídas e enraizadas na natureza quanto os homens; mas, na prática, eles se mostrariam mais distantes da conexão com o meio ambiente. Ou

8 Nos textos originais do pensamento ecofeminista de matriz social, muitas vezes, a palavra socialista é utilizada como sinônimo. Porém, como não necessariamente se referem ao socialismo científico ou marxista, inclusive porque ambos centram-se em figuras masculinas, lança-se mão apenas do termo social. 
seja, alguns homens lançam mão de seu poder para escapar das consequências de sua corporeidade (Mellor, 2000: 82).

Desde seus primeiros escritos, King rechaça a afirmação do alinhamento natural das mulheres com a natureza (Mellor, 2000: 83-84). Mesmo que a oposição natureza e cultura seja um produto cultural, podemos lançar mão de tal dicotomia para criar uma manifestação diferente, que integraria tanto as formas intuitivoespirituais associadas ao feminino quanto as racionais do conhecimento associado ao masculino. Em outros termos, extirpar a distinção natureza versus cultura e ciência versus espiritualidade seria o caminho para uma sociedade ecologicamente livre (King, 1983: 123).

Entretanto, apesar dos pontos dissidentes, tanto o ecofeminismo de afinidade/ espiritual quanto o social entendem que as mulheres têm sido o sacrifício ofertado pela cultura à natureza. E mais, que a relação entre o feminismo e a ecologia se respalda na ligação entre o jugo das mulheres e da natureza, enquanto reflexo da exploração e dominação das manifestações patriarcais e masculinizantes (King, 1990: 115).

Enquanto as espirituais colocam nas mulheres o poder da Deusa imanente e corporificada na natureza, as ecofeministas sociais afirmam que elas estão se organizando contra políticas dominadas por homens (Mellor, 2000: 64).

Dado o estabelecimento das distinções entre essas duas grandes correntes ecofeministas complementares entre si, é importante ressaltar queelas não se excluem, visto que os contornos principais são comuns e ambas opõem-se à dominação e às hierarquias ilegítimas (Warren, 200o: 46-47).

Sob essa lógica de pensamento, a literatura fantástica de Marion Zimmer Bradley (2017) toma forma. A arte consegue traduzir e elucidar com maestria o pensamento do seu tempo de gestação ao rememorar um pretenso passado.

\section{O enredo de As Brumas de Avalon}

Livros, atos e ações antecederam e prepararam o caminho para a germinação de ideias concretas da equidade das mulheres. Uma vez apresentado o pensamento ecofeminista, enquanto paradigma intelectual de conexão entre as características do patriarcado e da devastação da natureza, passa-se a discorrer sobre tais aspectos em As Brumas de Avalon.

A discussão terminológica do ecofeminismo é trabalhada também no contexto da ecocrítica. Na contemporaneidade, os estudos pioneiros da brasileira Angélica Soares (2009) e de Izabel Brandão (2003) são referência, bem como o marco inicial posto pelo livro organizado por Glotfelty \& Fromm (1996).

A partir de Glotfelty \& Fromm (1996), a noção de mundo expande-se para incluir efetivamente a ecosfera e a natureza. Soares (2009: 3) aduz sobre o espaço de resistência representado pela literatura frente "a diferentes formas de dominação 
biológica e/ou cultural". Izabel Brandão (2003), por sua vez, complementa sobre a problematização do corpo e a artificialidade binária entre natureza e cultura. Sob a égide desse pensamento, torna-se possível ponderar aspectos temáticos ecofeministas em As Brumas de Avalon.

A série de livros organizada com o nome de Ciclo de Avalon retoma em suas histórias mais famosas nuances da religiosidade de matriz celta, especialmente na deificação do sagrado feminino e na relação da mulher com a ciclicidade da natureza, da lua, das estações, da menstruação, da fêmea.

A relação cíclica é expressa por meio dos quatro ciclos naturais, assim como quatro são as fases da mulher. Luas nova, crescente, cheia, minguante. Estações de primavera, verão, outono, inverno. Fase pré-menstrual, menstrual, pré-ovulatória, ovulatória. Arquétipos femininos da donzela, da mãe, da feiticeira, da anciã (Grey, 2017).

As Brumas de Avalon é a coletânea mais famosa de Marion Zimmer Bradley e o primeiro livro que a condensa foi publicado inicialmente em 1979, mesmo período de florescimento do ecofeminismo e de retomada das intersecções desses quatro ciclos. A obra é considerada um clássico da literatura e narra a lenda de Rei Arthur e dos Cavaleiros da Távola Redonda. Mas, ao contrário de enfatizar as guerras e as conquistas arthurianas, o foco consiste na subjetividade das mulheres como agentes de imprescindível fortaleza para o desenrolar de todos os acontecimentos.

Os quatro livros de As Brumas de Avalon são A Senhora da Magia; Grande Rainha; O Gamo-Rei; e O Prisioneiro no Carvalho. A ideia consiste em: se lidos conjuntamente, traçam a linearidade dos acontecimentos responsáveis por narrar a história da personagem principal, a Morgana das Fadas.

Essa reinterpretação das lendas arthurianas e das histórias da Távola Redonda, de fato, traz personagens e objetos presentes no imaginário coletivo, tais quais o mago Merlin, a espada excalibur e o platônico triângulo amoroso entre Arthur, Lancelote e Gwenhwyfar. Mas, o grande diferencial de As Brumas de Avalon reside em, ao misturar realidade com fantasia, dar visibilidade e história às personagens antes vistas como planas. Morgana era apenas pintada como uma fada ou uma bruxa, sempre vilã nas histórias contadas no patriarcado. Não havia a explicitação do motivo pelo qual essa mulher teria tanta raiva do rei Arthur. Na obra em tela, a linha condutora da sucessão de fatos é exatamente a vida de Morgana, desde quando era criança até sua velhice, narrando suas aventuras em cortes reais, na ilha mística de Avalon e na travessia entre esses mundos.

Na história, Avalon é a terra sagrada escondida dos olhares comuns, que somente se releva pela magia, onde habitavam as antigas sacerdotisas pagãs, de cultos à Deusa, na sociedade matriarcal. De fato, a Ilha da Bretanha é o último lugar no qual o Império Romano chegou. Os romanos podem ser vistos como invasores e civilizadores, a depender do ponto de vista. Em sua chegada, ao fim da Antiguidade e no começo da Idade Média, um dos primeiros costumes a serem modificados era a religião. 
Quando abandonam os deuses gregos e convertem-se ao cristianismo, os romanos passam a evangelizar os povos locais, associando antigas religiões com a bruxaria de tom maléfico. Mas, mesmo com a saída dos romanos, a Bretanha ainda não queda completamente cristianizada, pois os poderes locais perpetuam a manutenção de suas lideranças, ainda que enfraquecidas.

Porém, em virtude de possíveis ou prováveis invasões bárbaras advindas da parte continental, bem como de povos selvagens ao norte da Ilha da Bretanha, a necessidade de fortalecimento e unificação se mostra necessária. Ou seja, os senhores vislumbram a necessidade de reunirem-se para conter ameaças externas. E, é nesse contexto, que Arthur é escolhido e torna-se rei.

A história de As Brumas de Avalon busca trazer outra religiosidade que não a patriarcal imposta pelos romanos: a de matriz celta. Para tanto, as personagens são pintadas com personalidades fortes e distintas entre si. Dentre as principais, tem-se Morgana, Arthur, Viviane, Lancelote e Gwenhwyfar.

Morgana das Fadas é, nessa versão escrita por Marion Zimmer Bradley, irmã mais velha de Arthur, que cose a bainha mágica da excalibur e a quem é deixada a incumbência de proteger o culto à Deusa. Arthur é o homem tolerante, crente da convivência pacífica entre religiões. Tanto que, ao tornar-se rei, agrega em sua corte conselheiros cristãos e pagãos, como o é Merlin, função exercida pelo druida mestre da antiga religiosidade.

Morgana e Arthur são sobrinhos de Viviane, a Senhora do Lado e da Ilha Sagrada; a sacerdotisa mais importante, sábia e respeitada de seu tempo. Lancelote, primeiro amor de Morgana, melhor amigo de Arthur, filho de Viviane; apaixona-se pela mulher mais fiel aos valores patriarcais: Gwenhwyfar.

Gwenhwyfar, esposa de Arthur e rainha, foi enviada por seu pai ao rei junto com seu dote, que continha uma enorme mesa ovalar feita de madeira, posteriormente conhecida como a távola redonda. Ela, acostumada pelos padres a temer a natureza atrás dos muros do castelo da mesma forma que é arisca ao paganismo e a tudo que escapa aos literais dizeres não escritos, cria uma desavença com Morgana, esta que nada faz além de ajudá-la com magia, quando expressa e rispidamente solicitada.

Honrando a sina de seus nascimentos, Morgana passa o resto de sua vida defendendo a face materna da divindade. Arthur, a trazer unidade para a Bretanha, de forma tolerante e pacífica; Viviane, a religiosidade; Lancelote, seu rei; Gwenhwyfar, seu medo frente ao desconhecido pagão.

Como uma boa novela de cavalaria, a obra demonstra a fidelidade dos cavaleiros ao rei e ao reino. Quanto às mulheres, releva a explorada condição feminina. Se pobres, o destino das mulheres seria trabalhar nas plantações e dar à luz o máximo de filhos e filhas que seu corpo suportasse. Se nobres, pertenceriam aos seus pais até serem entregues em casamento, independentemente de suas vontades, e negociadas como se fossem mais um objeto do dote.

Morgana e outras mulheres afiliadas à antiga religião matriarcal do culto à Deusa sofrem as mesmas mazelas de sua condição feminina quando saem de Avalon. 
É exatamente essa dualidade de tratamento que permite ser vislumbrada com mais clareza as questões teóricas ecofeministas na obra literária.

\section{Ecofeminismo e As Brumas de Avalon}

Academicamente, a corrente paradigmática ecofeminista cresce nos anos de 1970 e 1980, mesmo período em que são publicadas As Brumas de Avalon.

Em 1980, é realizada a 1aㅡ Conferência Ecofeminista - Mulheres e Vida na Terra - realizada em Amherst, cidade no condado de Hampshire, em Massachusetts, nos Estados Unidos, conectando a devastação do planeta com ameaças nucleares vindas de nações militaristas e da ação de grandes conglomerados empresariais. Essas mesmas questões beligerantes de Estados e empresas também afetava a vida das mulheres, na medida em que os mesmos valores masculinizantes também negavam às mulheres o direito à sexualidade de seu próprio corpo feminino (Monte, 2010).

Tanto a essencialidade espiritual quanto o viés da formação social ecofeministas são expostos na obra, relacionando a violência patriarcal no jugo da natureza e das mulheres. Quanto à formação social, demonstra como as práticas têm direta influência na construção das personalidades coletivas e individuais. Morgana, treinada por Viviane para se tornar uma grande sacerdotisa, é inteira e decidida sobre seus quereres e potencialidades enquanto mulher. Mas, ao ficar muito tempo fora de Avalon, perde a conexão com sua própria essência, aceita casar-se em uma união arranjada, sente vergonha de suas paixões e de quem é.

Morgana das Fadas, criada sob a religiosidade matriarcal, percebe as injustiças sociais fora de Avalon. Gwenhwyfar, por sua vez, cresce para se tornar a boa moça cristã, digna de ser rainha e mãe do futuro herdeiro ao trono. Mas, ao não conseguir manter nenhuma gravidez, germina em si a raiva a tudo que não siga os padrões ensinados a ela. Os mesmos padrões que não lhe trouxeram felicidade, mas apenas insatisfação da vida e nojo de seus desejos junto a Lancelote.

A fala de Gwenhwyfar e a cobrança que faz ao seu marido e rei Arthur, para que a conversão do paganismo para o cristianismo seja completa, fica evidente em trechos como o abaixo:

- Eu confessei os meus pecados - gritou Gwenhwyfar -, cumpri minha penitência e fui absolvida, não é pelos meus pecados que Deus nos castiga! Diga o que fará Arthur! Quando Deus lhe deu a vitória em monte Badon, jurou que colocaria o velho estandarte do dragão de lado e governaria como um rei cristão, mas deixou esse pecado inconfesso. Agora faça penitência por ele também, e deixe que Deus lhe dê a vitória deste dia como fez em monte Badon... Fique livre de todos os seus pecados e me dê um filho que possa reinar em Camelot depois de você! (Bradley, 2017: 609). 
Quanto à essencialidade espiritual ecofeminista, As Brumas de Avalon demonstram a imanência da Deusa, ou seja, a presença das diversas faces deificadas da Mãe na própria corporeidade das sacerdotisas. Por exemplo, a personagem Morgana representa os arquétipos da donzela, da mãe, da feiticeira e da anciã, a depender do momento da história e da necessidade de sua atuação. Ela sente um amor jovial por Lancelote, é a figura materna de Arthur, domina as artes das ervas, torna-se a mais sábia sacerdotisa de sua geração e invoca o fim: "Ceridwen, Deusa, Mãe, Anciã da Morte, Grande Corvo... Senhora da vida e da morte... Grande Porca, que come seus filhotes... eu a chamo, eu a invoco... se é realmente o que decidiu, cabe à senhora ir até o fim..." (Bradley, 2017: 738).

Em verdade, a narrativa, muito além de oferecer uma releitura do mito do Rei Artur, explora a ascensão do cristianismo e a santificação da Virgem Maria, Mãe de Deus. ${ }^{9}$ Em outros termos, as religiões matriarcais ainda se fazem presentes, mesmo que em segundo plano, por meio do marianismo. No decorrer da história, a autora vai colocando em xeque não o pensamento de Jesus, o Cristo Ressuscitado, mas a forma com a qual a religião imposta, primeiramente pelo Império Romano e depois para a unificação do reino em torno da figura de Arthur, depredou a cultura antes existente. E, como parte da manifestação cultural, a espiritualidade imanente, ou seja, aquela presente no corpo. Esse aspecto é observável no seguinte diálogo que Morgana tem ao fim de sua jornada com uma jovem freira:

\begin{abstract}
- Aqui temos a Mãe de Deus, Maria Imaculada - disse a moça. Deus é tão grande e terrível que sempre tenho medo diante do altar $d E l e$, mas, aqui na capela de Maria, nós, que somos suas virgens devotas, podemos vir a ela como nossa Mãe, também. E, veja, aqui temos pequenas estátuas de nossas santas, Maria, que amou Jesus e enxugou seus pés com os próprios cabelos, e Marta, que cozinhou para ele e repreendeu a irmã quando ela não foi ajuda-la... gosto de pensar em Jesus quando ele era um homem de carne e osso que fazia algo por sua mãe, quando transformou água em vinho, para que ela não ficasse infeliz por não haver vinho para todos. E aqui está uma estátua muito velha que nosso bispo nos deu, de sua terra natal... uma das santas deles, seu nome é Brígida...

$[\ldots]$

Mas Brígida não é uma santa cristã, ela pensou, até mesmo Patrício pensa assim. É a Deusa como é venerada na Irlanda (Bradley, 2017: 961).
\end{abstract}

A espiritualidade que permeia a análise da obra é definida por Phillip Sheldrake (2013: 4) como uma categoria de influência dentro da história geral dos povos e das religiões, tais como o cristianismo. Assim, tanto a cultura tem impacto

9 A rigor, Maria é mãe de Jesus. A Igreja Católica entende Maria como mãe de Deus, pois Jesus faz parte da Trindade Santa católica. Entretanto, essa questão teológica ultrapassa o alcance deste artigo. 
na espiritualidade quanto o inverso. Em termos cristãos, refere-se à maneira com a qual os valores fundamentais, os estilos de vida e as práticas relacionadas ao sagrado refletem no entendimento particular de Deus, da identidade e da transformação humana (Sheldrake, 2013: 7).

No que diz respeito à importância de pensar o corpo no ecofeminismo, a afirmação de Stacy Alaimo sobre a necessidade de pensar a materialidade biológica com suas "interconexões evolucionárias, históricas e continuadas com o mundo material" (Alaimo, 2017: 910) é pertinente. Assim, a carnalidade impõe-se enquanto locus teórico de análise.

As Brumas de Avalon defende que a veneração da divindade, apesar de utilizar como subterfúgio símbolos criados por homens em inspiração divina e no uso de matéria prima natural, como ouro, prata e mármore, seria verdadeiramente estabelecida num encontro despido de extravagâncias.

Em outras palavras, Deus está sob o Seu céu, não em qualquer morada construída pelas mãos dos homens, pois, por mais abençoadas e iluminadas que sejam, são a manifestação da Divindade e não a Divindade em si. Por mais que usem matérias primas naturais em sua construção, não são a natureza de fato. "Como se uma casa construída pelas mãos do homem pudesse ser convertida, pelas palavras de algum padre, em algum lugar de moradia para o Espírito que não era, definitivamente, obra humana" (Bradley, 2017: 306-307).

Além disso, mostra ritos pagãos ancestrais entendidos por religiosidades patriarcais como magia. Tais ritos, porém, são apenas o conhecimento tradicional passado de geração em geração, sobre ervas, crenças, frutos e frutas. Um conhecimento sobre a natureza zelado por mulheres.

A espiritualidade é importante para que as mulheres e os seres em geral transitem pela vida em temas como morte, sofrimento e perversidade, mas as ecofeministas espirituais se diferem quanto a defender a existência de uma deusa e quanto à importância de sua representação simbólica. Contudo, tendo em vista os efeitos dos símbolos religiosos, inclusive para aqueles que neles não creem, por fazerem parte da cultura na qual estão inseridas, a maioria das pensadoras dessa corrente defende a existência de símbolos exaltadores da feminilidade e, o mais importante, que não coloquem nas mulheres a culpa pelos males do mundo nem a obrigatoriedade de serem castas e puras para, só assim, serem dignas (Mellor, 2000: $74)$.

Palavras outras, rememorar e pensar na religiosidade matriarcal e da face materna da deidade é vista, ainda que não seja um consenso, como salutar por ecofeministas como Mary Daly (1993), Elizabeth Gould Davis (1972) e Carolyn Merchant (1980). Contudo, tais manifestações espirituais e do essencialismo ecofeminista como um todo contém um problema: colocar na responsabilidade da mulher mais um fardo, o de não poder errar e estar sempre propensa a compreender, a cuidar e a ajudar. Como se as mulheres devessem "ter um cuidado especial em fazer a vontade de Deus porque fora por meio de uma mulher que a humanidade havia 
caído no pecado original, e cada uma deveria ter consciência de que era sua tarefa se redimir daquele pecado original no Éden" (Bradley, 2017: 300).

Realmente, o Jardim do Éden é um mito e uma memória coletiva antiga de um tempo no qual os seres humanos estavam livres do trabalho e da luta, sem precisarem semear ou colher, pois tudo o que precisavam para sobreviver nascia das múltiplas espécies de árvores, com todos os animais da terra e as aves do ar. Mesmo não existindo de fato um Éden, essa história antiga, passada verbalmente de geração a geração e solidificada em escrituras bíblicas, não é por isso falsa (Aslan, 2018: 5758).

O mito transmite uma percepção particular de mundo e tenta explicar por que as coisas são como são. ${ }^{10} \mathrm{Ou}$ seja, o mito não diz como tudo deveria ser ou como é verdadeiramente (Aslan, 2018: 57-58). Nesse sentido, se outrora prosperou a ideia transmitida pelo conto do Éden, de que foi por meio de uma mulher que a humanidade passou a trabalhar e a sofrer, não há mais espaço para tal justificativa descabida.

A teoria ecofeminista de base espiritual vê que tal conexão entre mulheres e natureza não seria apenas simbólica, mas palpável em três exemplos. O primeiro reside na reprodução ou nascimento; o segundo, na produção ou na agricultura; e o terceiro, na provisão de nutrição ou cuidar. Em cada uma dessas formas de trabalho, as mulheres são as mediadoras entre a natureza e a humanidade (Salleh, 1991: 211). Ou seja, é da fêmea que se nasce, se produz, se gera o alimento.

Tendo isso exposto, as principais críticas feitas ao espiritualismo ecofeminista são: um, o fortalecimento de correntes Nova Era, de um neopaganismo surgido no seio das classes urbanas, bem como o comércio que o acompanha, de produtos, vestimentas, adornos e manutenção financeira de ambientes específicos, prioritariamente brancos, economicamente prósperos e em grandes cidades. Dois, os julgamentos ao cristianismo e outras religiões monoteístas masculinas, manifestadas através de arranjos patriarcais. Três, a baixa contemplatividade do feminismo negro (Mellor, 200o: 76). Quatro, uma aparente apropriação cultural de práticas religiosas e espirituais de comunidades indigenistas, aborígenes e tradicionais.

Ora, o ecofeminismo espiritual trata da afinidade, pois associa de forma consanguínea a luta das mulheres aos direitos de natureza, na celebração de seus corpos e dos valores centrados na mulher, como maternidade e alimentação. A corporeidade das mulheres é captável pela cosmologia de identificação das forças masculinas e femininas - de um deus transcendente versus uma deusa imanente (Mellor, 2000: 77).

Aparentemente as mulheres às quais o ecofeminismo se refere estariam mais próximas da natureza. Entretanto, a cultura fez com que elas preservassem e conservassem de forma holística, cíclica e intuitiva o pensar e o agir, ao mesmo passo que incentivou nos homens o desenvolvimento de um pensamento mais lógico e linear. Porém, mesmo na admissão de uma diferença biológica entre homens e

10 Assim como os mitos são pensados para solidificar uma realidade, acabam por fortalecê-la. E, justamente por isso, é preciso reler lendas com um olhar agregador, sem perpetuar injustiças. 
mulheres, o espírito das características atribuídas ao feminino também estaria disponível para homens se assim o decidirem abraçá-lo. Assim, as diferenças entre a proximidade de homens e mulheres com a natureza seriam, em última instância, não tão fundamentais assim (Mellor, 2000: 77).

Ainda que se assumam diferenças biológicas entre os sexos e distinções de gênero, não significa um conflito definitivo de interesses. As mulheres estariam mais perto da natureza, pois, em virtude de diversas razões, nunca a abandonaram completamente. Nesse sentido, o ressurgimento do feminino é uma forma de fazer as pazes com características socioculturais outrora tão rechaçadas e diminuídas (Mellor, 2000: 78), e mais, de repensar a própria masculinidade.

Se, por um lado, as ecofeministas espiritualistas partem da associação de mulheres e natureza; por outro, as sociais partem das desigualdades e dominações dentro da sociedade humana. Entretanto, essas categorias do espiritual e do social não são totalmente distintas, muito menos excludentes (Mellor, 200o: 78).

Por meio do estudo teológico feminista, é possível desmistificar a figura de Deus-Pai ${ }^{11}$ como um personagem literário masculino e, em seu lugar, mostrar uma face divina mais acolhedora, que ampara, conforta e entende. As instituições religiosas são reflexo da doutrina mais amplamente aceita em seu meio. Se o entendimento majoritário é androcêntrico, por certo a estrutura de organização também será.

A queda da figura da divindade como um ente masculino representa a crítica à visão dualista entre corpo e espírito. E mais: representa a crítica à visão negativa da corporeidade e, por consequência, das mulheres. Como são elas as responsáveis pela reprodução, a existência feminina é associada ao corpo mais facilmente do que a masculina. O corpo, por sua vez, é visto como o lar do perigo, da tentação e, assim, precisa ser controlado.

O ecofeminismo espiritual, manifestado por meio de teólogas feministas, representa a necessidade de repensar a doutrina majoritária das grandes religiões. "O corpo não está destinado a elevar-se a espírito. É o Espírito que escolhe fazer-se visível, no corpo" (Alves, 1984: 51), pois ambos são um só. O corpo não precisa mais ser visto como espaço de pecado, mas, sim, como manifestação da beleza da alma e do espírito.

\section{Reflexões sobre uma acepção ecofeminista em As Brumas de Avalon}

O mundo patriarcal é construído com base na ideia de superioridade e de dominação androcêntrica, ou seja, coloca o homem no centro da cultura e da vida. Porém, a figura do homem como núcleo das formações culturais é prejudicial tanto para a vida e liberdade das mulheres como das espécies humana e não humana, pois

11 Dentre a diversidade de manifestações religiosas e espirituais que podem entender a figura divina como uma força ou energia além do gênero, ao se falar de Deus-Pai e da atribuição do masculino à divindade, alude-se às teologias cristãs, como a católica. 
os mesmos adjetivos causadores da violência contra os corpos femininos também levam às mazelas ambientais.

Entretanto, o paradigma androcêntrico é questionado por diversas perspectivas de estudo e, dentre elas, o ecofeminismo. Ao analisarem-se as relações das mulheres com o meio ambiente, evidencia-se um sistema complexo de dominação que tem minado a vida de mulheres, animais e ecossistemas inteiros em rios, geleiras, desertos e oceanos.

A ideia nuclear do ecofeminismo repousa na transposição dos debates de jugo da mulher pelo homem, para a relação do homem e da natureza. O homem como representante da formação de cultura assentada em bases patriarcais e a natureza como o ambiente feminino explorado e dominado por essa cultura.

O ecofeminismo, além de transpor essa relação de jugo, coloca as características tipicamente atribuídas ao feminino, a exemplo do cuidado, do zelo, da atenção e da doação, como salvadoras do meio ambiente. As únicas características capazes de salvar a natureza. Como consequência, por vezes liga de forma essencialista a conexão da mulher e da natureza, porque a biologia feminina estaria intimamente ligada a ciclos naturais de forma mais evidente que a masculina. Essa essencialidade, entretanto, acaba evidenciando, em alguns aspectos, uma religiosidade imanente e presente também em cada uma das existências. Além da religiosidade, evidencia o contexto social que trata as mulheres como mais próximas à natureza e às práticas não remuneradas de cuidado.

A partir dessa análise, a coletânea literária de As Brumas de Avalon demonstra, de forma clara, uma acepção ecofeminista. Tanto na espiritualidade quanto na seara social, a prática e a ideia são evidenciadas por meio do enredo histórico e fantástico das personagens criadas por Marion Zimmer Bradley. A obra tornou-se um sucesso mundial e um clássico que encanta gerações de leitoras que fazem da narrativa um norte para a compreensão do mundo e da socialização imposta para homens e para mulheres ao longo da história mais recente do planeta.

\section{Referências}

ALAIMO, Stacy. (2017). "Feminismos transcorpóreos e o espaço ético da natureza: p. 909-934”. Revista Estudos Feministas. Florianópolis, v. 25, n. 2, mai-ago.

ALVES, Rubem. (1984). Creio na ressurreição do corpo. 3. ed. São Paulo: Edições Paulinas/CEDI.

ASLAN, Reza. (2018). Deus: uma história humana. Tradução: Marlene Suano. Rio de Janeiro: Zahar.

BRADLEY, Marion Zimmer. (2017). As Brumas de Avalon. São Paulo: Planeta do Brasil. 
BRANDÃO, Izabel. (2003). "Ecofeminismo e literatura: novas fronteiras críticas: 46149o”, In: BRANDÃO, Izabel; MUZART, Zahidé (Org.). Refazendo nós: ensaios sobre mulher e literatura. Florianópolis: Ed. Mulheres.

FERREIRA, Maria Luísa Ribeiro. (2009). As mulheres na Filosofia. Portugal: Fórum de Ideias.

DALY, Mary. (1990). Gyn/Ecology: The Metaethics of Radical Feminism. Boston: Beacon Press.

DALY, Mary. (1993). Beyond God the Father - Toward a Philosophy of Women's Liberation. Boston: Beacon Press.

DAVIS, Elizabeth Gould. (1972). The First Sex. Inglaterra: Penguin Books.

D'EAUBONNE, Françoise. (1980). "Le Feminisme ou la mort". In: MARKS, Elaine \& COURTIVRON, Isabelle de. New Feminisms: An Anthology. Massachusetts/Estados Unidos: University of Massachusetts Press.

FRANÇA, Vanessa de Vasconcellos Lemgruber França. (2019). Ecofeminismos e Direitos. Belo Horizonte. Dissertação (Mestrado em Direito) - Escola Superior Dom Helder Câmara, Belo Horizonte, mimeo.

FRANÇA, Vanessa de Vasconcellos Lemgruber França. (2016). A Extrafiscalidade Ambiental como Instrumento de Políticas Públicas. Monografia (Graduação em Direito) - Universidade Federal de Minas Gerais, Belo Horizonte, mimeo.

GARCIA, Carla Cristina. (2015). Breve História do Feminismo. 3. ed. São Paulo: Claridade, 2015. E-Book.

GLOTFELTY, Cheryll \& FROMM, Harold. (1996). The ecocriticism reader - landmarks in literary ecology. Athens / London: The University of Georgia Press.

KING, Ynestra. (1983). "Toward na Ecological Feminism and a Feminist Ecology". In: ROTHSCHILD, Joan (ed.). Healing the Wounds: The Promisse of Ecofeminism. Londres: Green Print.

MELLOR, Mary. (200o). Feminismo y ecologia. México: Siglo Veinteuno Editores.

MERCHANT, Carolyn. (1980). The Death of Nature: Women, Ecology, and the Scientific Revolution. Nova Iorque: Harper and Row. 
MONTE, Izadora Xavier do. (2010). Gênero e Relações Internacionais - Uma Crítica ao Discurso Tradicional de Segurança. Dissertação(Mestradoem Relações Internacionais) - Instituto de Relações Internacionais, Universidade de Brasília, Brasília, mimeo.

MOURÃO, Laís. (1997). O Futuro Ancestral - tradição e revolução científica a partir do pensamento de C. G. Jung. Brasília: Editora Universidade de Brasília.

SALLEH, Ariel. (1991). Book Review. Hypatia: journal of feminist philosophy. Issue 1.p. 206-2014, v.6.

SHELDRAKE, Philip. (2013). Spirituality: A Brief History. Second Edition. Nova Jersey: Blackwell Publishing.

SOARES, Angélica. (2009). "Apontamentos para uma crítica literária ecofeminista". Revista Garrafa. Rio de Janeiro, v.7, n. 20, abr-jun.

WARREN, Karen. (2000). Ecofeminist Philosophy: A Western Perspective on What It Is and Why It Matters. Rowman \& Littlefield Publishers.

WARREN, Karen J., (2015). Feminist Environmental Philosophy, The Stanford Encyclopedia of Philosophy (Summer 2015 Edition), Edward N. Zalta (ed.). Disponível em: <https://plato.stanford.edu/archives/sum2015/entries/feminismenvironmental/>. Acesso em: 11 jan. 2019.

Recebido em 30/05/2020.

Aceito em 20/06/2020. 